\title{
Internal Control, Financial Governance and Corporate Strategic Objectives Achievement
}

\author{
$\mathrm{Yu} \mathrm{Lu}^{1}$, Han Zhan ${ }^{2} \&$ Shiyu Xiao ${ }^{3}$ \\ ${ }^{1}$ Business School, Beijing Technology and Business University \\ ${ }^{2}$ Gies College of Business, University of Illinois at Urban-Champaign \\ ${ }^{3}$ Mendoza College of Business, University of Notre Dame \\ Correspondence: Yu Lu, Business School, Beijing Technology and Business University, China. E-mail: \\ luyu@btbu.edu.cn
}

Received: July 13, 2019

Accepted: August 7, 2019

Online Published: August 18, 2019

doi:10.5430/afr.v8n3p157

URL: https://doi.org/10.5430/afr.v8n3p157

\begin{abstract}
From the perspective of financial governance, this paper analyzes the impact of internal control on the achievement degree of corporate strategic objectives and the influence path, taking the A-share listed companies from 2014 to 2016 in Shanghai and Shenzhen Stock Exchanges as samples. The empirical analysis results show that there is a significant positive correlation between internal control and the achievement degree of corporate strategic objectives, and that financial governance mediates the correlation between internal control and the achievement degree of corporate strategic objectives. Further research shows that among various types of corporate strategies, cost leadership strategy and market share strategy are significantly and positively affected by internal control. However, technology leadership strategy is not affected by internal control. The paper also found that there is no significant correlation between internal control and strategy differentiation. These conclusions have a certain significance for listed companies to improve internal control, conduct financial governance and achieve their strategic objectives.
\end{abstract}

Keywords: internal control, financial governance, corporate strategic objectives achievement

\section{Introduction}

In recent years, impacted by slowed-down global economic growth and weak exports, China's economy has grown at a low rate and entered a new normal. The competitive pressure faced by Chinese enterprises has increased. How to maintain competitive advantages in the fierce market competition has become a crucial issue in practice and theory fields. Corporate strategy is the key to gain competitive advantages and the most important non-financial factor for investors to evaluate corporate value (Xue et al., 2005; Mazzei, 2017). Without effective strategy implementation, companies cannot achieve their strategic development objectives (Wang et al., 2018).

On the other hand, internal control is the fundamental control activity of a company, and it is an important guarantee for a company to cope with market risks and develop sustainably. However, previous discussions regarding the impact of internal control on enterprises were mainly based on the perspective of information disclosure. The influence factors and economic consequences of the internal control deficiency and its disclosure were studied from the aspect of governance (Doyle et al., 2007; Ashbaugh et al., 2008; Goh And Li, 2011; Newton et al., 2016). Zhu et al. (2011) believes that as a key link in corporate governance and the institutional arrangement for business management, internal control plays an important role in corporate development. The corporate development strategy is the highest goal of internal control (Yin and Zhang, 2016), and is an important part of designing and implementing internal control (Wu, 2012). So, with the implementation of The Basic Standard for Enterprise Internal Control, can the design of internal control help enterprises achieve their development strategic objectives? Previous research on internal control and corporate strategy was based on strategy management (Yu, 2013), system integration (Chi, 2009), transaction costs and resource base (Xu and Lin, 2010), etc. to discuss the relationship between internal control and corporate strategy, and there is little empirical evidence regarding this relationship. This paper takes internal control and development strategic objectives as starting points to analyzes the impact of internal control the achievement degree of corporate strategic objectives and the influence path from a new perspective of financial governance.

Compared with previous studies, the possible contributions of this paper are as follows. Firstly, different from the literature related to internal control and corporate strategy, this paper considers the impact of internal control on the 
achievement of corporate development strategic objectives and the influence path from the aspect of financial governance. Secondly, most existing research ignores the impact of endogeneity. This paper adopts the two-stage instrumental variable approach and fixed effect model (FEM) to reduce possible biases. Thirdly, most literature related to internal control and corporate strategy does not pay attention to the subdivision of the corporate strategy. This paper further analyzes different types of strategies and strategy differentiation, which is helpful in deeply investigating the mechanism and influence path of internal control on the achievement degree of corporate strategic objectives.

\section{Literature Review and Research Hypothesis}

\subsection{Internal Control and Corporate Strategy}

The connotations of the strategy include strategic objective, strategic path, and resource guarantee. The strategic objective is the expectation of major achievements anticipated by the strategic positioning, and the strategic path is the selection and plans of the means to achieve strategic objectives (Yang, 2012). The resource guarantee is the foundation to achieve corporate strategy. The strategic objective is the basic starting point to make the corporate strategy, the guideline for implementing the corporate strategy, and the evaluation standard for strategic control, reflecting the direction and expectation of operating activities (Davidson, 2003).

Based on the strategic management concept, the relationship between the implementation of internal control and corporate strategy essentially reflects the target of internal control. Internal control is the control activity to achieve the strategy, and it is a kind of strategy management (Chi, 2010). Various elements of internal control are centered on strategic objectives, forming an integrated whole. A clear strategy plan can ensure good business operation. Therefore, it is necessary to establish a formal mechanism in the process of corporate governance, that is, strategically-oriented internal control so that senior executives can actively exercise supervisory responsibilities. The characteristic of strategically-oriented internal control is that the internal control has been risen from local control to integrated framework and from activity level to all levels and integrated risks of a company (Schmidt and Brauer, 2010). With the change of economic and social environment, if companies want to survive and develop in fierce competition and improve their competitiveness, their internal control must be strategically oriented (Rowe, 2011). Strategically-oriented internal control can identify potential risks in a timely manner and take steps to modify the strategy and reduce losses.

Internal control itself is an execution system rather than a decision-making system, but the control in the decision-making process can provide reasonable assurance for the scientific positioning of strategic objectives, and the hierarchical authorization control and budget control in the process of implementing the strategy can ensure that the business operation meet the requirements of corporate strategic objectives. In terms of hierarchical authorization control, the juridical person's hierarchical authorization and approval system in the company should be improved, and the examination and approval nodes and corresponding authorities of each subdivision of each business such as credit and investment should be nailed down. For example, hierarchical authorization of investment business stipulates that "a high-risk investment of 500 million yuan or more is reported to the Strategy and Investment Committee of the Board of Directors, and that of 500 million yuan or less is submitted to Investment Commission for examination and approval", ensuring that the examination and approval nodes are in compliance with regulations. The implementation of a series of means such as hierarchical authorization can ensure effective implementation and effectiveness of the strategy (Bo and Lu, 2013; Sun, 2018). Capital hierarchical authorization system points out clearly the hierarchy of risk management related to expenditure of capital, sets different examination and approval authorities and levels for different hierarchies, fully implements management responsibilities, strengthens process monitoring and evaluation, promotes effective allocation of resources, and ensures the achievement of corporate strategic objectives (Liu, 2017).

Resources should be allocated rationally within budgets to improve resource utilization efficiency. The budget also emphasizes that with the participation of all departments and units of the company, guided by the business process and based on the internal division of responsibilities, responsibilities of investment, operation, maintenance, finance, human resource and other departments should be defined clearly, achieving effective connection between business budgets and financial budgets, and forming a working mechanism and responsibility mechanism with clear division of work and labor, clear responsibilities, mutual collaboration, and effective cooperation. Using the budget target as the main basis to allocate resources can effectively address the situation in which the company's strategy and budget target are segmented. The budget enables the functions of senior managers to be gradually focused on long-term resource planning and performance assessment of subordinates, transform the company's internal hierarchy from "form" to "substance", which can refine the company's development plans and annual operating goals, and which is conducive to monitoring the achievement of the strategic objectives for a series of quantitative planning arrangement 
of the overall business activities. Budget management can rationally allocate resources, strong internal control, discover loopholes and deficiencies in management, and reduce daily operating risks. Through the setting, execution, analysis, correction, assessment and other aspects of the budget target, it can rationally allocate the resource of the unit's human resource, finances, materials, etc., to achieve the established budget target, control operating costs, and improve economic efficiency (Zhao, 2019).

Kaplan and Norton (1996) combined traditional budgets with strategic and non-financial indicators through a balanced scorecard to make budgets more flexible and adaptable within the organization. The budget is the financial expression of the strategic plan (Wu, 2019). The budget that deviates from the corporate strategy in improper. The imperfect budget organization, disjoint cost budgets, single budget management model and assessment indicator, and insufficient information impede the effective development of corporate budget management and are not conducive for the company to making sound decisions and to achieve its strategic objective. The fundamental purpose of implementing an evaluation of the strategic budget is to better grasp the management. The strictness of the assessment is the fundamental guarantee for implementing a corporate strategy. If the assessment of budgets is not in place, the ultimate objective will not be achieved ( $\mathrm{Bu}, 2017)$. A company should strengthen budget and cost management, meet the needs of corporate strategic development from the aspects of financial resources and financial risk control, and delve into the financial data of the company to provide information support for the strategic development. A company should also take control as the core to carry out budget compilation and hierarchical decentralization, implement responsibility cost control, track the implementation during the budgeted period and give timely feedback, adjust budget execution according to the feedback, perform assessment and appraisal of budget management for employees at the end of budgeted period, improve the efficiency of internal work, and better achieve its strategic objective( $\mathrm{Si}, 2017)$.

An effective internal control escorts the company's strategic objective. The degree to which the internal control measures the achievement of its strategic objective is a signal of the overall effectiveness of the company's internal control (Han and Wang, 2009). Listed companies regard internal control as endogenous demand, positively impact productions and the achievement of their strategic objectives (Ye, 2011). Internal control focuses on the design and implementation of corporate strategic objectives. A company can achieve its strategic objective through effective recognizing and preventing various risks in business operations, thus enhancing core competitiveness. Whether the strategic objective of a company can be finally achieved depends largely on the establishment of internal control. Internal control is the key means for a company to implement its strategic objective and lays the foundation for the ultimate achievement. High-quality internal control can make the company's strategic objective better realized. Effective implementation of the internal control provides powerful and scientific support and a sustainable guarantee for the strategic objective of a company, and it is an important guarantee for the company to achieve phrased operating plans and develop sustainably strategic plans. Only the effectively designed and implemented internal control can act on corporate governance to achieve strategic objectives (Yu, 2013). An effective internal control implementation mechanism can moderately regulate and control the strategic activities of the enterprise and protect the achievement of its strategic objective. Hence, the better internal control, the more likely it is for a company to achieve its strategic objective. Therefore, the first hypothesis (H1), which is that there is a positive relationship between internal control and the achievement degree of strategic objectives, is proposed.

\subsection{Internal Control, Financial Governance and Strategic Objectives}

Previous literature proposed a framework based on norms of strategically-oriented internal control and derived from the theoretical analysis that internal control has a significant impact on the achievement of strategic objectives. Furthermore, what is the functioning path of internal control in achieving the anticipated strategic objectives? A large amount of research support is needed to answer this question. Most of the previous literature studied the relationship between internal control and corporate strategies form the perspectives of control management, system integration, transaction costs, resource base, etc. (Chi, 2019; Xu and Lin, 2010; Xu, 2013). Western scholars focus on analyzing corporate governance from the financial perspective, integrate the company's financial theory with corporate governance theory through the perspective of financial governance, and explore the intrinsic relationship and interdependence between corporate finance and corporate governance. Financial performance is an important criterion for evaluating the company's operating efficiency and development level, and the achievement of strategic objectives is mainly measured by financial indicators (Zhang, 2001). Therefore, this paper believes that internal control impacts the achievement of strategic objectives through financial governance. Financial governance is the main path to achieve strategic objectives through internal control.

The financial governance theory is the innovative theory of China's financial academia. There are different concepts including the concept of corporate governance subsystems, the concept of financial rights allocation, the concept of 
information and the concept of relationship coordination. This paper adopts the concept defined by Gao, etc. (2011) that financial governance includes: (1) Financial rights allocation, which examines mainly whether various stakeholders of the company can properly exercise their rights to make financial decisions; (2) Financial control, which examines the process of exercising financial rights; (3) Financial supervision, which inspects the supervision of execution process of financial rights by each functional departments and stakeholders; (4) Financial incentive, which examines whether the company has sufficient effective financial incentive mechanisms.

The essence of financial rights allocation in a company is that owners, executive officers and financial managers share financial rights and achieve optimal organizational efficiency under the equilibrium of authorization and control (Xie, 1997; Tang, 1997). Internal control adjusts and regulates corporate financial governance activities based on financial governance structure arrangements. Financial governance is the core of corporate governance and the soul of corporate governance (Zhang, 2002). Objectives of corporate governance objectives are mainly achieved through financial governance. Internal control and corporate governance are closely connected (Yang, 2015; Xie, 2002). The internal control system is an important means to improve corporate governance (Luo et al., 2019). The structure of corporate finance is the foundation of internal control (Yang and $\mathrm{Hu}, 2004)$. The internal environment, which includes development strategy, governance structure, organization setup, allocation of authorities and responsibilities, supervision system, human resources policy, corporate culture and social responsibility, is the basis for the implementation of internal control (Yang, 2012). The control and oversight functions and roles of the Board of Directors, especially the emphasis on internal financial control and risk management, affect the company's financial governance. The mechanism of financial governance mainly includes decision-making, financial incentive, and constraint mechanisms. Internal controls ensure that this mechanism works effectively and provides effective and smooth information and communication. Internal control improves governance efficiency through financial governance, thereby maintaining the balance of interests of internal and external stakeholders.

In the process of implementing strategies, financial resources play a role of safeguard, incentive, and constraint to help a company achieve its strategic objective.

The basic goal of financial resource allocation is to achieve the company's strategic objective. Starting from the contractual relationship of enterprise property rights, Corporate financial governance theory conducts reasonable formal and informal institutional arrangements for financial rights allocation within the company to protect the interests of stakeholders. As a contractual arrangement, financial governance rationally allocates residual claims and control rights through specific governance means to form self-discipline and mutual-constraint mechanisms. Collaborative financial control represents optimal resource allocation and is a means of adding value. High-level financial governance can reduce agency costs, information asymmetry, and risk level, improve business efficiency and investment efficiency, improve business performance, improve financial reporting quality and gain public support (Gao and Fang, 2014). Strategic management also requires enterprises to stand at the height of the company's strategic development and use financial management and other means to provide decision support for the company's strategic decision-making and strategic reformation.

Internal control achieves corporate strategic objectives through financial governance. Financial governance helps to improve the efficiency of corporate investment, positively affecting business performance, and it is an important way to improve the quality of listed companies. This function is mainly achieved through financial control and financial supervision. The establishment of various financial systems is the guarantee for achieving financial management objectives, and the implementation of internal control is the way to ensure the implementation of the strategy. Perfect internal control and risk management, and a sound financial control system enable enterprises to provide timely feedback, rationally allocate capital, effectively manage risks, and improve operating efficiency. The better the internal control, the stronger the financial governance effect, the less the agency problems in the enterprise operation, the lower the information asymmetry risk, the lower the capital cost of the enterprise, the higher the management efficiency, the greater the incentive and restraint effect, the better the business performance will be, the easier it is to achieve the company's strategic objective. Internal control optimizes the overall value of the enterprise through the analysis of the operation chain and value chain, enhancing the competitive advantage of the enterprise; identifies and assesses risks faced by the company and adopts affirmative measures through analyzing the business environment, including the analysis of the macro-environment, the specific industrial environment, and the internal environment of the enterprise; determines the strengths and weaknesses of the company, identifies possible threats $(\mathrm{He}, 2008)$ through competitive capability analysis, enhancing the achievement degree of corporate strategic objectives ultimately. Internal control is a means of corporate governance. Financial statements are the ultimate things. Internal control helps a company achieve its strategy through finance, and the achievement of the strategy is expressed through finance. In summary, the second hypothesis of this paper is as follows. 
H2: Financial governance mediates the correlation between internal control and the achievement degree of strategic objectives.

\section{Research Design}

\subsection{Samples and Data}

This paper takes all A-share listed companies of Shanghai and Shenzhen Stock Exchanges from 2014 to 2016 as the initial sample, and screens sample according to the following criteria: (1) All cross-listed companies are excluded; (2) All ST and *ST companies are excluded; (3) Financial and insurance companies are excluded; (4) Data-missing companies are excluded. After screening, the final sample includes 2,760 listed companies. The internal control data comes from the DIB Internal Control and Risk Management Database, the research and development data are from the WIND database, and other data comes from the Guo Tai'an CSMAR database

\subsection{Variable Definition}

\subsubsection{Achievement degree of strategic objectives (Strategy)}

The strategic objective is difficult to measure. Bin Lin et al. (2014) examined the achievement degree of strategy before, during and after the event from three aspects of the operating plan, competitive advantage and systemic risk. Foreign scholars also use ROE and text analysis to measure. This paper focuses on postmortem analysis and uses ROE to measure strategy. Referring to Yan Tong et al. (2016), this paper also constructs an index system, which is the total score of the proportion of sales expenses to operating income, the ratio of fixed assets to the number of employees, the ratio of the number of employees to total assets, and the proportion of sales expenses to total assets, to measure achievement degree of strategic objectives.

\subsubsection{Internal Control (IC)}

This paper uses the DIB Internal Control Index and the DIB Internal Control Information Disclosure Index to measure internal control.

\subsubsection{Financial Governance (Finance)}

Gao et al. $(2011,2013,2015)$ constructed the Financial Governance Index, which consisted of four aspects: financial rights allocation, financial control, financial supervision, and financial incentives. Xiao and Qin (2011) used the type I equity agency cost, the type II equity agency cost, return on assets (ROA) and the corporate value to measure financial governance. Zhou and Chen (2014) measure financial governance with core financial performance indicators such as earnings per share (EPS), return on equity (ROE), the growth rate of main operating income and growth rate of net assets. This paper uses the Financial Governance Index (Gao et al., 2015) to measure the quality of financial governance.

Referring to relevant literatures (Yin and Zhang, 2016; Xia Wang, 2017), the control variables in this paper include Fshare (the shareholding ratio of the largest shareholder), Size (the natural logarithm of total assets), Debt (debt-to-asset ratio), Tobin (Tobin's Q Ratio), Location (listed companies in Shanghai take 1; listed companies in Shenzhen take 0), Ownership (state-owned enterprises take 1; non-state-owned enterprises take 0), Age (from year of founding to year of collecting data), and industry and annual dummy variables.

\subsection{Model}

According to the research ideas, in order to test the impact of internal control on strategic objectives, that is, the hypothesis $1(\mathrm{H} 1)$, the following model is built:

$$
\text { Strategy }_{i t+1}=\delta_{0}+\delta_{1} I_{C}{ }_{i t}+\delta_{2} \text { Controls }_{i t}+\varepsilon_{i t}
$$

In order to test the mediating effect of financial governance on internal control and strategic objectives, that is, the hypothesis 2 (H2), this paper draws on the method of Wen et al. (2004) to build the following model:

$$
\begin{aligned}
\text { Finance }_{i t} & =\delta_{0}+\delta_{1} \text { ICi }_{t}+\delta_{2} \text { Controls }_{i t}+\varepsilon_{i t} \\
\text { Strategy }_{i t+1} & =\delta_{0}+\delta_{1} \text { IC }_{t}+\delta_{2} \text { Finance }_{i t}+\delta_{3} \text { Controls }_{i t}+\varepsilon_{i t}
\end{aligned}
$$

\section{Empirical Analysis Results}

\subsection{Descriptive Statistics and Correlation Analysis}

\subsubsection{Descriptive statistics}

Table 1 shows the descriptive statistics of the variables. The mean, median, 75\% quantile and maximum value of Strategy are 0.0488, 0.0610, 0.1090, and 9.1019, respectively. The mean, minimum value, maximum value, and standard deviation of internal control (IC) are 639.4066/1,000, 0, 898.65, and 108.498, respectively. The results 
indicate that the overall internal control of Chinese listed companies is average, and the numerical differences are large. The mean, minimum value and maximum value of Finance are 55.5584, 21.2153, and 76.6667, respectively, which indicates that the overall efficiency of financial governance needs to be improved, and the quality gap is significant. The mean value of Fshare is 0.3518 , the minimum and maximum values are 0.0029 and 0.8941 , respectively, and the standard deviation is 0.1530. Besides, the mean of Debt and Tobin are 0.4660 and 2.8765, respectively. The average natural logarithm of company size is 22 . The sample companies listed on the Shenzhen Stock Exchange accounted for $35.3 \%$ of the total, and state-owned enterprises accounted for $46.3 \%$. The average age of sample companies is 18 .

Table 1. Descriptive Statistics

\begin{tabular}{cccccccc}
\hline Variable & Mean & $\begin{array}{c}\text { Standard } \\
\text { Deviation }\end{array}$ & Minimum & Q2 & Median & Q3 & Maximum \\
\hline Strategy & 0.0488 & 0.4597 & -14.8189 & 0.0214 & 0.0610 & 0.1090 & 9.1019 \\
IC & 639.4066 & 108.498 & 0 & 0 & 656.085 & 697.39 & 898.65 \\
Finance & 55.5584 & 8.2326 & 21.2153 & 23.4028 & 54.8971 & 74.7917 & 76.6667 \\
Fshare & 0.3518 & 0.1530 & 0.0029 & 0.0389 & 0.3347 & 0.4523 & 0.8941 \\
Debt & 0.4660 & 0.2142 & 0.0091 & 0.0277 & 0.4606 & 0.6306 & 2.2052 \\
Tobin & 2.8765 & 18.7019 & 0.0625 & 0.0778 & 1.7381 & 3.0024 & 965.001 \\
Size & 22.2909 & 1.3143 & 14.9416 & 21.442 & 22.1222 & 22.996 & 30.5406 \\
Location & 0.3530 & 0.4780 & 0 & 0 & 0 & 1 & 1 \\
Ownership & 0.4630 & 0.4987 & 0 & 0 & 0 & 1 & 1 \\
Age & 17.6657 & 6.8594 & 3 & 14 & 17 & 21 & 78 \\
\hline
\end{tabular}

4.1.2 Correlation analysis

The Pearson correlation analysis results show that the correlation coefficients between the independent variables are less than 0.5 , indicating that there is no serious multicollinearity issue in this model.

Table 2. Correlation Test

\begin{tabular}{cccccccc}
\hline & Fshare & Debt & Tobin & Size & Location & Ownership & Age \\
\hline Fshare & 1 & & & & & & \\
Debt & 0.0481 & 1 & & & & & \\
Tobin & -0.0238 & -0.0729 & 1 & & & & \\
Size & 0.1806 & 0.4918 & -0.1547 & 1 & & & \\
Location & -0.0156 & -0.1429 & 0.0113 & -0.1919 & 1 & & \\
Ownership & 0.0252 & -0.0165 & 0.0219 & 0.0078 & -0.0108 & 1 & \\
Age & -0.0568 & 0.1328 & -0.0048 & 0.058 & -0.1420 & 0.0359 & 1 \\
\hline
\end{tabular}

4.2 Empirical Analysis of Internal Control and Strategic Objectives

Table 3 reports the empirical test results of internal control and strategic objectives. The results show that the coefficient of $I C$ is significantly positive at the $1 \%$ level, indicating that the level of internal control is positively correlated with the achievement degree of corporate strategic objectives, which is consistent with the expectation of this paper. The results also indicate that the higher the internal control level, the more likely the enterprise can reasonably guarantee the achievement of the development strategic objectives and that internal control is the means to achieve corporate strategic objectives. The above results support Hypothesis 1.

In terms of control variables, the Debt is significantly negative at the level of $1 \%$, indicating that the level of corporate debt can affect the achievement of corporate strategic objectives to a certain extent. The coefficient of Size is significantly positive, indicating that the company's size is positively related to the degree of achievement of strategic objectives. The results are consistent with the conclusions of previous studies. Other control variables including ownership structure, company growth ability, listing location, nature of property rights, and company age are not significantly related to corporate strategic objectives. 
Table 3. Internal Control and Corporate Strategic Objectives

\begin{tabular}{ccc}
\hline Variable & Coefficient & T-value \\
\hline C & $-0.4552^{* *}$ & -2.45 \\
IC & $0.0004^{* * *}$ & 4.22 \\
Fshare & 0.0391 & 0.65 \\
Debt & $-0.1729^{* * *}$ & -3.46 \\
Tobin & 0.0001 & 0.17 \\
Size & $0.0147^{*}$ & 1.76 \\
Location & 0.0141 & 0.34 \\
Ownership & 0.0054 & 0.29 \\
Age & 0.0001 & 0.08 \\
INDUS/YEAR & & \\
Sample size & Control \\
Adj_R & & \\
F-value & \multicolumn{3}{c}{0.0086} \\
\hline
\end{tabular}

Note: *,**, and *** means significance at $10 \%, 5 \%$, and $1 \%$ level, respectively.

4.3 Mediating Effect of Financial Governance on the Correlation Between Internal Control and Corporate Strategic Objectives

In order to test the impact of financial governance on the relationship between internal control and corporate strategic objectives, this paper examines the impact of internal control on financial governance and the role of financial governance on corporate strategic objectives. As can be seen from tables 3 and 4, coefficients of $I C$ in models 1 and 2 , and coefficients of $I C$ and Finance in model 3 are significantly positive, which indicates that the mediating effect of financial governance is significant. The results show that internal control of enterprises positively affects the efficiency of financial governance, and the efficiency of financial governance also positively affects the degree of achievement of the strategy. Internal control affects the efficiency of financial governance and then functions in the company's strategy. The better internal control is, the higher the quality of financial governance, the more likely the company is to achieve its strategic objective. The quality of financial governance plays a significant intermediary role in the correlation between internal control and corporate strategic objectives. Internal control impacts the achievement of corporate strategic objectives through financial governance. Therefore, hypothesis 2 gains support.

Table 4. Mediating effect of financial governance

\begin{tabular}{|c|c|c|c|c|c|}
\hline Model 2 & & & Model 3 & & \\
\hline Variable & Coefficient & T-value & Variable & Coefficient & T-value \\
\hline C & $-2.7997 * * *$ & -11.37 & $C$ & $-0.5229 * *$ & -2.77 \\
\hline \multirow[t]{2}{*}{ IC } & $0.0013 * * *$ & 11.67 & IC & $0.0003 * * *$ & 3.96 \\
\hline & & & Finance & $0.0024 * *$ & 2.11 \\
\hline Fshare & $0.2136^{* * *}$ & 2.67 & Fshare & 0.0337 & 0.56 \\
\hline Debt & $-0.6312 * * *$ & -9.53 & Debt & $-0.1642 * * *$ & -3.27 \\
\hline Tobin & -0.0016 & -2.49 & Tobin & 0.0001 & 0.18 \\
\hline Size & $0.1158 * * *$ & 10.44 & Size & 0.0124 & 1.47 \\
\hline Location & 0.0229 & 0.42 & Location & 0.0102 & 0.24 \\
\hline Ownership & -0.0214 & -0.88 & Ownership & 0.0045 & 0.25 \\
\hline Age & 0.0006 & 0.33 & Age & 0.0002 & 0.12 \\
\hline INDUS/ YEAR & Control & & $\begin{array}{l}\text { INDUS/ } \\
\text { YEAR }\end{array}$ & Control & \\
\hline Sample size & 2760 & & Sample size & 2760 & \\
\hline Adj_R $R^{2}$ & 0.1164 & & Adj_R2 & 0.0098 & \\
\hline F-value & 28.95 & & F-value & 2.95 & \\
\hline
\end{tabular}

Note: *, **, and *** means significance at $10 \%, 5 \%$, and $1 \%$ level, respectively. 


\subsection{Empirical Analysis of Internal Control and Corporate Strategy Differentiation}

Some corporate strategies deviate from industrial or mainstream trends, resulting in strategy differentiation (Ye et al., 2014). Can internal control effectively reduce risks resulting from strategy differentiation? To test this impact, this paper further examines the correlation between internal control and strategy differentiation. Referring to Tang et al. (2011), the strategy differentiation is calculated by subtracting the industrial average of the corporate strategy indicator from the indicator of each company, dividing the result by the standard deviation of the indicator in order to standardize it, taking the absolute values and then averaging them. The larger the indicator, the more significant the strategy differentiation is. According to the regression results in Table 5, there is no significant correlation between internal control and strategy differentiation, indicating that internal control has no impact on corporate strategy differentiation, which is different from the conclusions of Yin and Zhang (2016). They found that high-quality internal control can effectively restrain the deviation of strategy differentiation and prevent and reduce the risks and losses of strategic decisions. The results of this paper illustrate the need for the assurance of internal control regardless of the degree of strategy differentiation. Internal controls help to increase the effectiveness of strategy differentiation while reducing the risk of loss from strategy differentiation.

Table 5. Internal control and strategy differentiation

\begin{tabular}{|c|c|c|}
\hline Variable & Coefficient & T-value \\
\hline$C$ & $0.9460 * * *$ & 3.45 \\
\hline$I C$ & -0.0001 & -0.42 \\
\hline Fshare & 0.1369 & 1.54 \\
\hline Debt & $-0.1998 * * *$ & -2.71 \\
\hline Tobin & $0.0047 * * *$ & 6.51 \\
\hline Size & -0.0095 & -0.77 \\
\hline Location & $-0.5635 * * *$ & -9.21 \\
\hline Ownership & $0.0518 *$ & 1.91 \\
\hline Age & $-0.0034 *$ & -1.68 \\
\hline INDUS/ YEAR & \multicolumn{2}{|c|}{ Control } \\
\hline Sample size & \multicolumn{2}{|c|}{2760} \\
\hline Adj_R ${ }^{2}$ & \multicolumn{2}{|c|}{0.1026} \\
\hline F-value & \multicolumn{2}{|c|}{25.27} \\
\hline
\end{tabular}

Note: *,*, and *** means significance at $10 \%, 5 \%$, and $1 \%$ level, respectively.

\subsection{Empirical Analysis of Internal Control and Corporate Strategy Grouping}

There are various aspects of corporate strategy (Tong et al., 2016). According to scores of strategies from high to low scores, Yang and $\mathrm{Wu}$ (2017) divided corporate strategies into four groups, which were the offensive, defensive, analytical and reactive strategy. However, this method separates the strengths and weaknesses of the company's operations. For example, a company that adopts an offensive strategy is a strong company with competitive advantages. Referring to Jia et al. (2015), this paper divides strategies into cost leadership strategy, market share leadership strategy and technology leadership strategy. Low-cost strategy, high-tech strategy, and high market share strategy are divided according to operating profit margin, R\&D expenditure level and sales revenue ratio. Ricky (2011) proposed that different competitive strategies affect the requirements of companies' internal control and that compared with the differentiated strategy that emphasizes customer needs, the cost leadership strategy emphasizes more on the role of strict internal control in achieving strategic objectives.

The sample is subjected to a group regression analysis using a model (1). It can be seen from Table 6 that in the low-cost strategy group and the high market share strategy group, the coefficients of $I C$ are significantly positive at the level of $1 \%$, while in the high-tech strategy group, the coefficient of $I C$ is not significant. The above results show that internal control significantly affects the cost leadership strategy, less impacts the market share leadership strategy and does not impact significantly the technology-leadership strategy. It can be seen that internal control affects the achievement degree of strategic objectives differently and thus needs to be treated differently. 
Table 6. Internal Control and Different Types of Corporate Strategies

\begin{tabular}{cccc}
\hline Variable & Cost-leadership & Technology-leadership & Market share leadership \\
& Strategy & Strategy & $-0.7367^{* *}$ \\
& $-0.1056^{*}$ & $-0.1357^{*}$ & $(-2.12)$ \\
IC & $(-1.67)$ & $(-0.3)$ & $0.0004^{* * *}$ \\
& $0.0002^{* * *}$ & 0.0003 & $(2.79)$ \\
Fshare & $(4.76)$ & $(1.78)$ & $0.2049^{*}$ \\
& $0.0621^{* * *}$ & -0.1555 & $(1.66)$ \\
Debt & $(3.47)$ & $(-1.11)$ & $-0.2710^{* * *}$ \\
& 0.0009 & -0.0998 & $(-2.86)$ \\
Tobin & $(0.05)$ & $(-0.83)$ & 0.0001 \\
& $0.0016^{* * *}$ & 0.0014 & $(0.14)$ \\
Size & $(2.63)$ & $(0.23)$ & 0.0239 \\
& 0.0035 & 0.0012 & $(1.56)$ \\
Location & $(1.25)$ & $(0.06)$ & 0.0900 \\
& -0.0078 & -0.0335 & $(1.04)$ \\
Ownership & $(-0.64)$ & $(-0.34)$ & 0.0053 \\
& 0.0022 & 0.0013 & $(0.15)$ \\
Age & $(0.39)$ & $(0.03)$ & 0.0020 \\
& -0.0007 & -0.0009 & $(0.73)$ \\
INDUS & $(-1.5)$ & $(-0.31)$ & Control \\
YEAR & Control & Control & Control \\
\hline Sample size & Control & Control & 920 \\
Adj_R ${ }^{2}$ & 920 & 920 & 0.0133 \\
F-value & 0.0441 & 0.0057 & 1.95 \\
\hline
\end{tabular}

Note: *,**, and *** means significance at $10 \%, 5 \%$, and $1 \%$ level, respectively.

\subsection{Robustness Test}

To test the reliability of the above research conclusions, the following three robustness tests are conducted.

\subsubsection{Endogenous Issue}

When an enterprise decides on the strength of its internal control, it will predict the economic consequences based on the current situation, which means that the internal control behavior of the enterprise has strong endogeneity. The conclusions drawn from the OLS regression are likely to be pseudo-correlated. In order to mitigate the impact of endogenous problems on the research results, this paper adopts two-stage instrumental variable regression. This paper uses one phrase lagged data of internal control as the instrumental variable of IC to carry out two-stage least square regression, and the coefficient of internal control is still significant. The empirical results (Table 7) support the hypothesizes of this paper. In this paper, the model of Hypothesis 2 is also tested, and there is no endogeneity problem.

Table 7. Endogeneity Issue

\begin{tabular}{ccc}
\hline Variable & Coefficient & T-value \\
\hline C & -0.2096 & -1.34 \\
IC & $0.0002^{* *}$ & 2.41 \\
Fshare & 0.0086 & 0.17 \\
Debt & $-0.1016^{* *}$ & -2.44 \\
Tobin & 0.0000 & 0.11 \\
Size & 0.0071 & 1.02 \\
Location & 0.0036 & 0.10 \\
Ownership & -0.0045 & -0.29 \\
Age & -0.0008 & -0.66 \\
INDUS/YEAR & & \\
Sample size & Control \\
R & & \\
Wald & 0.0098 & \\
\hline
\end{tabular}

Note: *,**, and $* * *$ means significance at $10 \%, 5 \%$, and $1 \%$ level, respectively. 


\subsubsection{Fixed Effect Regression}

In order to avoid the conclusion that the research conclusion is affected by the missing company variables, this paper uses the fixed effect regression method to verify the robustness of the conclusion. Table 8 shows that after controlling the individual differentiation of companies, the regression results remain unchanged. The coefficient of internal control is still significantly positive, and the result of the control variable is basically consistent with the main regression. The results of the fixed effect model are consistent with the previous results, indicating that the model settings do not affect the results of this paper.

Table 8. Fixed effect regression

\begin{tabular}{ccc}
\hline Variable & Coefficient & T-value \\
\hline C & -0.3261 & -1.46 \\
IC & $0.0004^{* * *}$ & 4.12 \\
Fshare & 0.0810 & 1.13 \\
Debt & $-0.1312^{* *}$ & -2.16 \\
Tobin & 0.0019 & 0.70 \\
Size & 0.0049 & 0.49 \\
Location & 0.0154 & 0.38 \\
Ownership & -0.0039 & -0.02 \\
Age & 0.0013 & 0.78 \\
INDUS/YEAR & & \\
Sample size & Control \\
Adj_R & & \\
F-value & \multicolumn{2}{c}{0.0782} \\
\hline
\end{tabular}

Note: *,**, and *** means significance at $10 \%, 5 \%$, and $1 \%$ level, respectively.

\subsubsection{Substitution Variables to Measure Internal Control and Corporate Strategy}

There are several ways to measure internal control and corporate strategy. In this paper, the substitution variables of internal control and corporate strategy are used to repeat the previous regression done before to test robustness. The results are not substantially different, indicating that the hypothesizes of this paper are still valid.

Table 9. Regression of substitution variables

\begin{tabular}{llllll}
\hline \multicolumn{2}{l}{ Substitution variable of internal control } & \multicolumn{3}{l}{ Substitution } & variable of corporate strategy \\
\hline Variable & Coefficient & T-value & Variable & Coefficient & T-value \\
\hline C & $-0.3764^{* *}$ & -2.03 & C & $3.5854^{* * * *}$ & 8.93 \\
IC & $0.0028^{*}$ & 1.81 & IC & $0.0006^{* * *}$ & 3.02 \\
Fshare & 0.0531 & 0.88 & Fshare & $0.3363^{* * *}$ & 2.58 \\
Debt & $-0.1862^{* * *}$ & -3.72 & Debt & $0.4696^{* * *}$ & 4.35 \\
Tobin & 0.0001 & 0.18 & Tobin & $0.0147^{* * *}$ & 13.95 \\
Size & $0.0175^{* *}$ & 2.09 & Size & $-0.1596^{* * *}$ & -8.82 \\
Location & 0.0246 & 0.59 & Location & -0.0943 & -1.05 \\
Ownership & 0.0049 & 0.26 & Ownership & 0.0401 & 1.01 \\
Age & 0.0001 & 0.05 & Age & 0.0025 & 0.85 \\
INDUS/YEAR & Control & & INDUS/YEAR & Control & \\
\hline Sample size & 2760 & & Sample size & 2760 \\
Adj_R & 0.0033 & & Adj_R2 & 0.1058 & \\
F-value & 1.71 & F-value & 26.12 &
\end{tabular}

Note: $*, * *$, and $* * *$ means significance at $10 \%, 5 \%$, and $1 \%$ level, respectively. 


\section{Conclusion}

The research question in this paper is whether internal control affects and how it affects the achievement of the corporate strategic objectives. Different from previous studies, taking the A-share listed companies in Shanghai and Shenzhen Stock Exchanges in 2014-2016 as the research objectives, this paper theoretically analyzes and empirical tests whether internal control contributes to the achievement of corporate strategic objectives and the influence path from a unique perspective of financial governance. The study found that internal control is an effective governance mechanism to significantly improve the achievement of corporate strategic objectives, and that and this effect is mainly achieved through the mediating effect of financial governance. The specific empirical conclusions are as follows. Firstly, internal control affects the corporate strategy by impacting the quality of financial governance, that is, internal control is positively acting on financial governance, and financial governance is also acting positively on corporate strategic objectives. Secondly, among the three types of corporate strategies, internal control is significantly positively correlated with cost leadership and market share leadership strategy, while is not significantly correlated with technology leadership strategy. Thirdly, there is no significant correlation between internal control and strategy differentiation.

The research in this paper is practically significant. First of all, under the current economic situation, listed companies and their management can help enterprises achieve their strategic development objectives by implementing effective internal control. In addition, in recent years, relevant state departments have continuously issued various policies and regulations to encourage listed companies to improve the effectiveness of internal control. The research in this paper shows that, in terms of the corporate strategy, the implementation of internal control has a significant positive impact on the company and the realization of this impact can be interpreted from the perspective of the financial governance effect. Therefore, regulators and policymakers can use this as a reference to continue to encourage listed companies and non-listed companies to design and implement high-quality internal control and take measures to promote the effective operation of internal control to ensure the ultimate achievement of corporate strategic objectives.

\section{References}

Ashbaugh - Skaife, H., Collins, D. W., Kinney, W. R. \& LaFond, R. (2008). The Effect of SOX Internal Control Deficiencies and Their Remediation on Accrual Quality. The Accounting Review, 83(1), 217-250. https://doi.org/10.2308/accr.2008.83.1.217

Chi, G. H. (2009). Implementation Mechanism of Regulation of Internal Control: Strategy Orientation and System Integration Accounting Research, 2009(9), 66-71.

Chi, G. H. (2010). Model of Enterprise Internal Control Evaluation System Based on Management Perspective. Accounting Research, 2010(10), 126-126.

Doyle, J. T., Ge, W. \& McVay, S. E. (2007). Accruals Quality and Internal Control Over Financial Reporting. SSRN Electronic Journal. https://doi.org/10.2139/ssrn.789985

Gao, M. H. (2015). China Listed Company Financial Governance Index Report (2015). Economic Science Press.

Goh, B. W. \& Li, D. (2011). Internal Controls and Conditional Conservatism. The Accounting Review, 86(3), 975-1005. https://doi.org/10.2308/accr.00000041

Hoskisson, R. (1999). Theory and Research in Strategic Management: Swings of a Pendulum. Journal of Management, 25(3), 417-456. https://doi.org/10.1016/S0149-2063(99)00008-2

Jia, J. F., Tang, G. Y., Li, J.P., Wang, W. J. \& Shan, X. (2015). The Impact of Manager Competency and Strategic Orientation on Firm Performance. Management World, 2015(02), 120-132.

Li, W. A. \& Dai, W. T. (2013). Corporate Governance, Internal Control, Risk Management: A Framework of Relations Based on the view of Strategic Management. Journal of Audit \& Economics, 2013(4), 3-12.

Lin, B., Lin, D. J., Hu, W, M, Xie, F. \& Yang, Y. (2014). Goal-Oriented Internal Control Index Research. Accounting Research, 2014(8), 16-24.

Mazzei, M. J. \& Noble, D. (2017). Big data dreams: A framework for corporate strategy. Business Horizons, 60(3), 405-414. https://doi.org/10.1016/j.bushor.2017.01.010

Newton, N. J., Persellin, J. S., Wang, D. \& Wilkins, M. S. (2016). Internal Control Opinion Shopping and Audit Market Competition. The Accounting Review, 91(2), 603-623. https://doi.org/10.2308/accr-51149

Rowe, W. (2012). Dominant CEO, deviant strategy, and extreme performance: the moderating role of a powerful board. Strategic Direction, 28(4). https://doi.org/10.1108/sd.2012.05628daa.005 
Schmidt, S. L. \& Brauer, M. (2006). Strategic Governance: how to assess board effectiveness in guiding strategy execution. Corporate Governance: An International Review, 14(1), 13-22. https://doi.org/10.1111/j.1467-8683.2006.00480.x

Tong, Y., Sun, J. \& Lu, C. (2016). Prospects for Internal Control Research from the Perspective of Strategic Orientation and Value Creation. Scientific Decision Making, 2016(5), 28-49.

Van Essen, M., Carney, M., Gedajlovic, E. R. \& Heugens, P. P. (2014). How does Family Control Influence Firm Strategy and Performance? A Meta-Analysis of US Publicly Listed Firms. Corporate Governance: An International Review, 23(1), 3-24. https://doi.org/10.1111/corg.12080

Wang, B. Q., Hou, C. R. \& Sun, J. (2018). Research on the Influence of Corporate Strategy on Business Performance. China Soft Science, 2018(01), 127-137.

Wen, Z. L., Chang, L., Hou, K-T. \& Liu, H. Y. (2004). Testing and Application of the Mediating Effect. Acta Psychologica Sinica, 36(5), 614-620.

Xie, Z. H. (2007). Internal Control, Corporate Governance and Risk Management: Relationship and Integration. Accounting Research, 2007(10), 37-45. https://doi.org/10.2469/dig.v37.n4.4858

Xu, W. L., Sun, F. H., Wang, Z. W. \& Qian, X. H. (2008). Dimensional Structure and Measurement of Chinese Enterprise Strategy Execution. China Industrial Economics, 2008(10), 97-108.

Xue, Y. K., Qi, D. Q. \& Wei, H. N. (2005). Analysis on the Status Quo of Implementation of Chinese Enterprise Strategy and the Determinants of Its Implementation. Management World, 2005(9), 88-89.

Yang. Q. X. \& Liao, T. T. (2017). Internal Control, Technical Innovation and the Ability to Value Creation. Chinese Journal of Management, 14(8).

Yang, X. S. (2005). A Bran-new Canto Composed for Academic Research on Internal Control. Accounting Research, 2005(7), 49-54.

Yang, Y. H. \& Hu. Y. (2004). Tentative on the Junction of Corporate Governance and Internal Control. Accounting Research, 2004(10), 14-18.

Ye, K. T. \& Hu. Y. (2014). The Value Relevance between Corporate Strategic Differences and Accounting Information. Accounting Research, 2014(5), 44-51.

Yin, Z. P. \& Zhang, Z. G. (2016). Manager Tenure, Internal Control and Strategic Differences. China Soft Science, 2016(12), 132-143.

Yu, R. (2013). Study of the Strategic Management Framework Rooted in Internal Control Auditing. Auditing Research, 2013(6), 108-112.

Zhang, P. \& Yang, X. S. (2018). Exploration of Internal Control Mode in Chinese Local Cultural Situation-Based on Case Study of Longjiang Shipyard in Ming Dynasty. Management World, 2018(2), 161-175.

Zhu, H. J., Zhang, S. Y. \& Gao, H. W. (2011). The Theme and Review of China's Internal Control Research since the 21st Century-Based on the Analysis of Seven Major Domestic Journals such as Accounting Research from 2000 to 2010. Accounting Research, 2011(11), 59-66. 